\title{
EXTRAÇÃO DE AÇÚCARES DO GRÃO DE MILHO DE 1,18MM EM DIFERENTES TEMPOS DE COZIMENTO
}

\author{
L. C. NOGUEIRA ${ }^{1}$, G. U. ALCANTARA ${ }^{1}$; S. M. MOYA ${ }^{1}$ e G. H. G. COSTA $^{2}$ \\ ${ }^{1}$ Universidade do Sagrado Coração, Centro de Ciências Exatas Sociais e Aplicadas \\ E-mail para contato: lukas_conegundes@hotmail.com
}

RESUMO - Em decorrência da crescente demanda por etanol no mercado brasileiro, buscam-se novas matérias-primas que possam complementar a atual produção. Entre estas, destaca-se o milho, que apresenta ciclo de 4 a 5 meses e pode ser cultivado nas áreas de renovação de canaviais. Embora essa tecnologia já esteja em operação no Brasil, ainda há pontos que podem otimizar e aumentar os rendimentos industriais. Entre esses, deve-se destacar os reflexos do tempo de cozimento sobre a quantidade de açúcares extraídos em grãos de reduzida granulometria. Assim, o objetivo do trabalho foi avaliar os reflexos do processamento de milho com granulometria de $1,18 \mathrm{~mm}$ em diferentes tempos de cozimento. O delineamento experimental foi inteiramente casualizado, com 3 tratamentos e 3 repetições. Os grãos foram misturados a água acidulada na proporção de $200 \mathrm{~g} / \mathrm{L}$, aquecidos até a ebulição por 60,90 e 180 minutos, e resfriados a $80-90^{\circ} \mathrm{C}$. Nestas condições, dosou-se enzima $\alpha$-amilase, mantendo o meio em agitação por 30 minutos. A seguir, a pasta foi caracterizada quanto ao Brix, Açúcares Redutores Totais (ART), Amido e pH. Observou-se que o aquecimento por tempo prolongado resultou em aumento do Brix e do Amido, sem aumentar o teor de ART, resultante da evaporação de água e consequente concentração de sólidos. Conclui-se que o tempo de 60 minutos é o mais recomendado para a extração do amido de grão de milho de granulometria de $1,18 \mathrm{~mm}$.

\section{INTRODUÇÃO}

Atualmente o setor sucroenergético apresenta significativa importância na economia do Brasil, sendo responsável pela produção de açúcar, etanol e energia elétrica, originados do processamento agroindustrial da cana-de-açúcar. Considerando-se o bioetanol, observa-se que na safra 2014/15 foram produzidos 30,4 bilhões e, estima-se que, para a safra 2015/2016, sejam produzidos aproximadamente 27,8 bilhões de litros (CONAB, 2016).

Entretanto, verifica-se elevada demanda atual por este biocombustível, resultante da crescente frota de veículos "flex-fuel" impulsionada pelos incentivos governamentais à indústria automobilística. Estima-se que a frota destes veículos cresça acentuadamente nos próximos anos (BICALHO, 2011).

Neste contexto, se faz necessário a busca por alternativas que possam complementar a produção de etanol no país, objetivando atender a futura demanda por este combustível. Desta maneira, destaca-se o milho, que apresenta ciclo de 3 a 5 meses e pode ser cultivado nas áreas de renovação de canaviais (AGRIC, 2011). 
Cabe destacar que em seu desenvolvimento vegetativo, a planta armazena as moléculas de glicose produzidas durante o processo fotossintético em grãos, na forma de amido. Admite-se que a composição química do grão de milho em porcentagem de massa seca consiste em $72,7 \%$ de amido, $10,1 \%$ de proteína, 3,4\% de lipídeos, 5,2\% de fibras e 1,9\% de cinzas (PAES, 2006; SRICHUWONG et al., 2010).

Neste modelo de produção, o milho é cultivado durante o ano, sendo os grãos armazenados em silos e processados na entressafra da cana-de-açúcar, período em que a usina está inativa decorrente da não maturação desta cultura. Desta maneira, as unidades agroindustriais aumentam seu tempo de operação efetiva durante o ano, saindo dos atuais 270 dias para 330 dias. Deve-se destacar que os equipamentos necessários para esta produção são anexados aos atuais parques industriais, resultando nas Usinas Flex (Cana e Milho) (FAIAD NETO, 2014).

Embora esta tecnologia seja utilizada e difundida em países como Estados Unidos e China, se faz necessário à adaptação do processo as condições operacionais brasileiras, tais como as cultivares amplamente comercializadas no país, o tempo de cozimento, a granulometria dos grãos, as leveduras utilizadas pela fábrica e a influência do tempo de armazenamento dos grãos sobre o processo fermentativo.

Assim, o objetivo do projeto foi avaliar os reflexos do processamento de milho com granulometria de $1,18 \mathrm{~mm}$ em diferentes tempos de cozimento.

\section{MATERIAIS E METÓDOS}

O experimento foi instalado no Laboratório de Biomassa e Bioenergia da Universidade Sagrado Coração (USC), localizada no município de Bauru-SP, no segundo semestre de 2016.

O milho foi obtido de centros comerciais de Bauru-SP, sendo posteriormente triturados até granulometria de $1,18 \mathrm{~mm}$, utilizando-se triturador de potência de $1,5 \mathrm{cv}-60 \mathrm{~Hz}$ e, posteriormente, classificados através de sistema de peneiras de $187 \mathrm{~W}-50 / 60 \mathrm{~Hz}$.

Os grãos foram misturados a água acidulada (pH 5,0-5,5) na proporção de $200 \mathrm{~g} / \mathrm{L}$ (Figura 1), sendo posteriormente aquecidos até a ebulição (cozimento) por 60, 90 e 180 minutos. As soluções foram resfriadas a $80-90^{\circ} \mathrm{C}$, dosando-se a enzima $\alpha$-amilase (300KNU/g) objetivando a hidrólise do amido. As pastas foram mantidas nessas condições sob agitação constante (40 rpm) por 30 minutos.

Ao final do tempo, as amostras foram resfriadas a temperatura ambiente, filtradas em peneira de 20 mashes, e caracterizadas quanto aos açúcares redutores totais (MILLER, 1959), Brix, pH (CTC, 2005) e amido (CHAVAN et al., 1991).

O delineamento experimental foi inteiramente casualizado com 3 tratamentos (tempos de cozimento) e 3 repetições. Os dados foram submetidos a análise de variância pelo teste $\mathrm{F}$, e as médias comparadas segundo teste de Tukey 5(\%). 
Figura 1 - Amostras antes do cozimento.

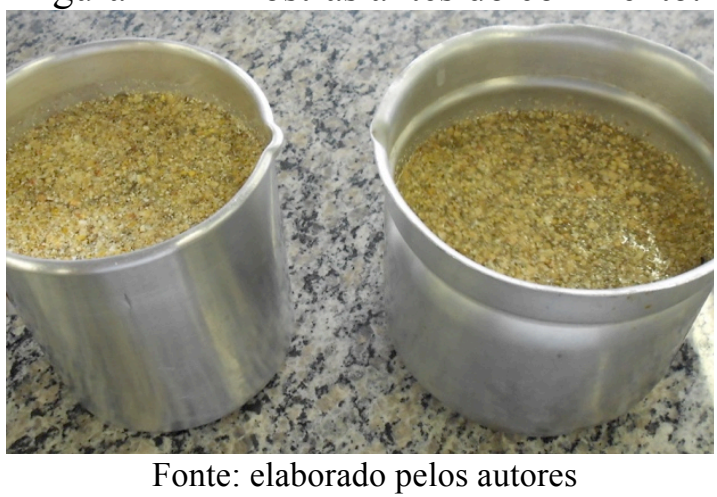

\section{RESULTADOS E DISCUSSÕES}

$\mathrm{Na}$ Tabela 1, estão apresentados os valores obtidos para Brix, Açúcares Redutores Totais (ART), Amido e pH das pastas de milho após extração em diferentes tempos de cozimento.

Observou-se que o Brix foi maior para o tempo de 180 minutos. Isto pode ser decorrente do processo de concentração de sólidos promovido pela evaporação de água em elevados tempos de cozimento. Entretanto, os valores são similares aos obtidos em mostos preparados a partir de caldo de cana, tais como os demonstrados por Macri et al. (2014) e Montijo et al. (2014), que determinaram teores de $16^{\circ}$.

Neste sentido, pode-se verificar ainda que os teores de ART na pasta foram superiores para o tratamento de 180 minutos, entretanto, os valores não diferiram significativamente dos demais tempos de cozimento. Estes valores são similares aos obtidos em caldo de cana, uma vez que Montijo et al. (2014), observaram teores da ordem de 14\% para mosto preparado a partir desta matéria-prima.

Considerando-se o amido, determinou-se que quanto maior o tempo de cozimento, maior o teor desta biomolécula na pasta. Este comportamento é similar ao observado para o Brix, que provavelmente foram influenciados pela evaporação de água. Cabe destacar ainda, que o processo de extração retira moléculas de amilopectina, que apresentam ligação $\alpha-1,6$. Esses compostos não são hidrolisados pela $\alpha$-amilase, sendo necessária a utilização de enzimas denominadas amiloglucosidade (FERREIRA, 2015). Avaliando-se o pH, verificou-se que não houve diferença entre as amostras. Ou seja, o tempo de cozimento não altera o $\mathrm{pH}$ da pasta. 
Tabela 1 - Valores médios obtidos para Brix, Açúcares Redutores Totais (ART), Amido e pH das pastas de milho que foram submetidas ao processo de cozimento por 60, 90 e 180 minutos, Bauru-SP Safra 2016/2017

\begin{tabular}{|l|l|l|l|l|}
\hline Tratamentos & Brix $\left(^{\circ}\right)$ & ART $(\%)$ & Amido $(\%)$ & pH \\
\hline Tempo (min) & $10,32^{* *}$ & $0,71 \mathrm{~ns}$ & $32,39^{* *}$ & $0,50 \mathrm{~ns}$ \\
\hline 60 & $17,1 \mathrm{~B}$ & $13,7 \mathrm{~A}$ & $0,30 \mathrm{~B}$ & 5,9 \\
90 & $18,4 \mathrm{~B}$ & $13,7 \mathrm{~A}$ & $0,41 \mathrm{~B}$ & 5,9 \\
180 & $23,4 \mathrm{~A}$ & $15,8 \mathrm{~A}$ & $1,21 \mathrm{~A}$ & 6,0 \\
\hline DMS & 4,46 & 6,14 & 0,38 & 0,11 \\
CV $(\%)$ & 9,05 & 16,98 & 23,56 & 0,79 \\
\hline
\end{tabular}

Letras diferentes na mesma coluna indicam diferença significativa segundo o teste de Tukey (5\%). **significativo ao nível de 1\% de probabilidade. DMS - Desvio Mínimo Significativo. CV - Coeficiente de Variação

\section{CONCLUSÃO}

A partir dos resultados obtidos no experimento, pode-se concluir que o tempo de 60 minutos é o mais recomendado para a extração do amido de grão de milho de granulometria de $1,18 \mathrm{~mm}$.

\section{REFERÊNCIAS}

AGRIC. Informação sobre o mundo agrícola, 2011. Disponível em: $<$ http://www.agric.com.br/producoes/milho_verde.html>. Acesso em: 12/03/2017.

BICALHO, R. GEE: Grupo de economia e energia, 2011. Disponível em: $<$ http://jornalggn.com.br/blog/ronaldo-bicalho/estimacao-da-frota-brasileira-deautomoveis-flex-e-a-nova-dinamica-do-consumo-de-etanol-no-brasil-a-partir- $>$ Acesso em: 13/03/2017.

CHAVAN, S. M.; KUMAR, A.; JADHAV, S. J. Rapid quantitative analysis of starch in sugarcane juice. International Sugar Journal, Glamorgan, v. 93, n. 107, 1991.

CONAB - Companhia Nacional de Abastecimento. Acompanhamento da safra brasileira: $3^{\circ}$ Levantamento da safra de cana-de-açúcar, 2016. Disponível em: $<$ http://www.conab.gov.br/OlalaCMS/uploads/arquivos/16_12_27_16_30_01_boletim_ cana_portugues_-3o_lev_-_16-17.pdf $>$. Acesso em: 13/03/2017.

CTC - Centro de Tecnologia Canavieira. Manual de métodos de análises para açúcar. Piracicaba, Centro de Tecnologia Canavieira, Laboratório de análises, 2005. Disponível em CD ROM.

FAIAD NETO, C. $15^{\circ}$ Seminário Brasileiro Agroindustrial: Usina da Sobrevivência. STAB: Ribeirão

Preto, 2014.

Disponível

em: 
$<$ http://stab.org.br/15sba/web/01_usina_flex_cezar_faiad_dedini.pdf $>$. Acesso em: $14 / 03 / 2017$.

FERREIRA, O. E. Produção de etanol a partir de sorgo sacarino com tratamento enzimático. 2015. 79 f. Tese de doutorado, Faculdades Ciências Agrárias e Veterinárias, Universidade Estadual Paulista, Jaboticabal, 2015.

MACRI, R.C.V.; COSTA, G.H.G.; MONTIJO, N.A.; SILVA, A.F.; MUTTON, M.J.R. Moringa extracts used in sugarcane juice treatment and effects on ethanolic fermentation. African Journal of Biotechnology, v.13, n.42, 2014.

MILLER, G.L. Use of de dinitrosalicylic acid reagent for determination of reducing sugar. Analytical Chemistry, v.31, n.3, 1959.

MONTIJO, N.A.; SILVA, A.F. COSTA, G.H.G.; FERREIRA, O.E.; MUTTON, M.J.R. Yeast CA-11 fermentation in musts treated with brown and green propolis. African Journal of Microbiology Research, v.8, n.39, 2014.

PAES, M.C.D. Aspectos Físicos, Quimicos e Tecnológicos do Grão de Milho. (Embrapa Milho e Sorgo. Circular Técnica, 75). Sete Lagoas, MG: Dezembro, p.6. 2006.

SRICHUWONG, S.; GUTESA, J.; BLANCO, M.; DUVICK, S. A.; GARDNER, C.; JANE, J.L. Characterization of Corn Grains for Dry-Grind Ethanol Production. Journal of ASTM International, v.7, n.2. 2010. 